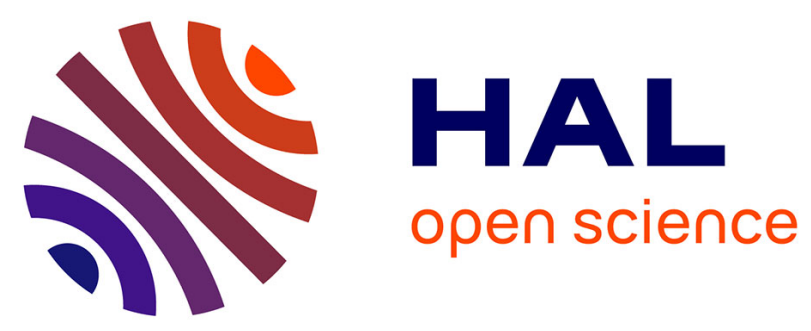

\title{
Who are the voluntary leaders? Experimental evidence from a sequential contribution game
}

\author{
Raphaële Préget, Phu Nguyen Van, Marc Willinger
}

\section{To cite this version:}

Raphaële Préget, Phu Nguyen Van, Marc Willinger. Who are the voluntary leaders? Experimental evidence from a sequential contribution game. Theory and Decision, 2016, First online: 11 May 2016 (4), 10.1007/s11238-016-9550-3 . hal-01300195

\section{HAL Id: hal-01300195 \\ https://hal.science/hal-01300195}

Submitted on 8 Apr 2016

HAL is a multi-disciplinary open access archive for the deposit and dissemination of scientific research documents, whether they are published or not. The documents may come from teaching and research institutions in France or abroad, or from public or private research centers.
L'archive ouverte pluridisciplinaire HAL, est destinée au dépôt et à la diffusion de documents scientifiques de niveau recherche, publiés ou non, émanant des établissements d'enseignement et de recherche français ou étrangers, des laboratoires publics ou privés. 


\title{
Who are the Voluntary Leaders? \\ Experimental Evidence from a Sequential Contribution Game
}

\author{
Raphä̈le Préget ${ }^{\mathrm{a}}$, Phu Nguyen-Van ${ }^{\mathrm{b}}$, Marc Willinger ${ }^{\mathrm{c} *}$ \\ ${ }^{a}$ LAMETA, INRA, Montpellier, France \\ ${ }^{\mathrm{b}}$ BETA CNRS, Université de Strasbourg, France \\ ${ }^{\mathrm{c}}$ LAMETA, Université de Montpellier, Montpellier, France
}

December 2015

\begin{abstract}
We rely on the methodology of Fischbacher et al. (2001) in order to identify subjects' behavioral types. We then link the likelihood to act as a leader in a repeated public goods game to the elicited behavioral types. The leader in a group is defined as the subject who voluntarily decides in the first place about his contribution. The leader's contribution is then reported publicly to the remaining group members who take their contribution decisions simultaneously. Our main findings are that leaders emerge in almost all rounds and that subjects who are identified as conditional cooperators are more likely to act as leaders than other types, e.g. free-riders or triangle-contributors. We also find that voluntary leaders, irrespective of their behavioral type, contribute always more than followers. However the presence of leadership does not prevent the decay that is commonly observed in linear public goods experiments.
\end{abstract}

JEL-classification H41, C92

Keywords Public Goods, Experimental Economics, Voluntary Contribution Mechanism, Leadership.

\footnotetext{
* Corresponding author at: LAMETA, UFR d'Economie, Avenue Raymond DUGRAND - Site de Richter C.S. 79606, 34960 MONTPELLIER CEDEX 2, France Tel +33 (0)4 34432519

E-mail addresses: preget@supagro.inra.fr (R. Preget), nguyen-van@unistra.fr (P. Nguyen-Van), marc.willinger@lameta.univ-montp1.fr (M. Willinger)
} 


\section{Introduction}

We provide new experimental evidence about leadership in a voluntary contribution game. We identify the leader as the subject who decides to act as the first mover, while later movers are identified as followers. Followers observe the leader's contribution before choosing their own contribution. Why are some individuals willing to act as a leader and others prefer to act as followers in such games? An important reason is "leading by example", i.e. individuals acting as leaders commit to large contributions with the intention to trigger reciprocity from the other group members, by showing the "good example". In contrast, taste for conformity, risk-aversion, strategic reasoning are possible reasons why other individuals prefer to "wait and see" before choosing their contribution. However there might also exist intrinsic motivations underlying subjects' choices and which are related to their social preferences. In social dilemma games where group efficiency and self-interest are in conflict, some subjects typically free ride while others behave cooperatively. Individuals' cooperativeness might therefore be an important driver of their propensity to act as a leader. A key reason is that cooperatively inclined individuals are more optimistic about others' cooperativeness as shown by Gächter et al. (2012). However cooperativeness is rarely unconditional. As vastly documented from the experimental literature on voluntary contributions, most individuals are of the conditional cooperative type (e.g., Keser and Van Winden 2000; Fischbacher et al. 2001; Frey and Meier 2004, Neugebauer et al. 2009; Fischbacher and Gächter 2010). Conditional cooperators are individuals who are willing to contribute (more) to the public good if others contribute (more). Reciprocity, fairness and inequity aversion are among the motives that are likely to underly conditional cooperation. Anyway, conditional cooperators might have a stronger preference for acting as a follower rather than for acting as a leader, because as a follower they are in the most favorable position for conditioning their contribution on the leader's. Furthermore, most conditional cooperators are selfishly biased (see Neugebauer et al. 2009 and Fischbacher and Gächter 2010), i.e. they tend to condition their own contribution on observed contributions with a downward bias, which means that they exploit to some extent the leader's contribution. Conditional cooperators who are aware of the existence of such a bias or, who are conscious that they might be matched with individuals who are not conditonal cooperators (e.g. free-riders), should be less likely to volunteer to act as a leader.

While the above reasons lead us to expect conditional cooperators to be more prone to behave as followers than as leaders, it is still an open question which behavioral type is more likely to take the lead when a voluntary contribution mechanism is set up. There exists a substantial experimental literature about leadership in public good games. Many laboratory experiments found that first movers tend to make larger contributions than later movers, and that later movers' contributions increase in first mover's contributions (Moxnes and van der Heijden 2003; Gächter and Renner 2003, 2007; Güth et al. 2007; Levati et al. 2007; Potters et al. 2007; Pogrebna et al. 2011; Gächter et al. 2010; Rivas and Sutter 2011; Masclet et al. 2012; Kumru and Vesterlund 2010; Arbak and Villeval 2013, Drouvelis and Nosenzo 2013). Similar results 
were also observed in field experiments (Shang and Croson 2009; Martin and Randal 2008; Alpizar et al. 2011).

A few experimental papers already addressed the issue of endogenous leadership in public goods games. Haigner and Wakolbinger (2010), Rivas and Sutter (2011) and Arbak and Villeval (2013) ${ }^{1}$ provided an experimental setting in which subjects could volunteer to take the lead in their group. These studies differ in the way voluntary leadership was implemented. In the experiment of Haigner and Wakolbinger (2010) a randomly selected subject had to choose between leading or following, while the remaining three other group members had to make a decision simultaneously after observing the eventual "leader's" contribution decision. In the endogenous treatment of Rivas and Sutter (2011), subjects who wanted to act as a leader in a round had to make their contribution within 15 seconds at the beginning of the round. The contribution of the leader, if any, was observable by the followers who had to make their contribution decisions simultaneously. Arbak and Villeval (2013) implemented a two-stage game: In stage 1, each group member had to decide whether to lead or not. In case several group members wanted to lead, one of them was randomly selected and his contribution was revealed to the others. In stage 2, the other group members had to choose their contributions simultaneously after eventually observing a leader's contribution ${ }^{2}$.

A common finding of experiments with endogenous leadership is that the average group contribution is larger when a leader voluntarily emerges compared to situations where either a leader is imposed or no one volunteers to act as a leader. In the three experiments mentioned above, leaders emerged frequently in the voluntary leadership treatments: groups had a leader about $60 \%$ of the time in Arbak and Villeval (2013) and $85 \%$ of the time in Rivas and Sutter (2011).

The question whether and why some individuals are more likely to act as a leader remains however an open one. We propose to make a step forward by eliciting leaders' and followers' contribution profiles. To our knowledge, Gächter et al. (2012) is the only paper that addressed the issue of the leaders' profiles, by eliciting subjects' cooperativeness and their beliefs about others' cooperativeness. The authors categorize each subject's cooperativeness according to her conditional contribution vector in the role of a follower. By allowing each subject to play both the leader's role and the follower's role, own cooperativeness can be related to own contribution as leader. After choosing their decision as first and second mover, subjects were also asked to predict the level of contribution of the second mover with whom they would be matched as a first mover. The expected level of contribution can be taken as a measure of

\footnotetext{
${ }^{1}$ Voluntary leadership was also studied by Potters et al. (2005) but in a situation of asymmetric information where the value of the MPCR was private information of the potential leader. In Dannenberg (2015) the leader was randomly selected and in one of the treatments he had the choice to lead by example (making a public binding contribution) to lead by words (making a public non-binding announcement of his contribution) or not to lead.

${ }^{2}$ The first stage eliminated candidates to become a leader were allowed to modify their initially proposed contribution in stage 2 .
} 
optimism. Gächter et al. (2012) suggest that a group is likely to perform best when the leader is cooperatively inclined. They showed that this result is partly due to a false consensus effect: "cooperative leaders are more optimistic than non-cooperators about the cooperativeness of followers". Because Gächter et al. (2012) relied on the strategy method to observe subjects' choices, the positions in the sequential game were assigned exogenously. Indeed, each subject had a $50 \%$ chance to act as a leader and $50 \%$ chance to act as a follower. Therefore, in contrast to Haigner and Wakolbinger (2010), Rivas and Sutter (2011) and Arbak and Villeval (2013), subjects could not volunteer to act as a leader. The Gächter et al.'s (2012) data is therefore not suitable for answering the question about which behavioral type is most likely to act as a leader. Nevertheless, their data clearly shows that there exists a positive correlation between a subject's cooperativeness and his contribution as a leader.

Although there are good reasons to expect conditional cooperators to be more likely to choose to contribute as followers than as leaders, as previously discussed, empirical evidence is missing. We fill this gap by exploring the issue based on an experiment designed to identify subjects' behavioral types before they participate in a voluntary contribution game. The experiment involves a two stages game. In the first stage, we elicit individuals' behavioral types, according to their conditional contribution to a group project. We rely on the incentivized methodology proposed by Fischbacher et al. (2001) and Fischbacher and Gächter (2010) to categorize participants either as free riders (FR), conditional cooperators (CC), triangle contributors (TC) or others $(\mathrm{O})^{3}$. In the second stage, participants play a multiple rounds voluntary contribution game in which they can volunteer to act as a leader. Each round was organized as follows: in the first 60 seconds each participant could decide about his group contribution. The earliest contribution, defined as the leader's contribution, was publicly announced to the other group members. Once the leader's contribution was announced, the remaining group members (the followers) had to decide about their contributions simultaneously. In the case no leader contribution was announced during the 60 seconds time interval, all the group members had to take their contribution decisions simultaneously (noleader players).

Our data clearly show that $\mathrm{CC}$ individuals are the most likely to act as a leader compared to the other types. We also confirm the previous findings of Haigner and Wakolbinger (2010), Rivas and Sutter (2011) and Arbak and Villeval (2013). As a secondary contribution, we perform an original data analysis by exploiting the panel structure of our data. We rely on Wooldridge's (2005) dynamic nonlinear panel data model which is particularly well suited for data consisting of repeated interactions in partner groups.

The remainder of the paper is organized as follows. In section 2 we describe our experimental design. The results are reported and analyzed in section 3 . Section 4 concludes.

\footnotetext{
${ }^{3}$ There is some analogy between the categorization of Gächter et al. (2012) in terms of Non Cooperators, Strong Cooperators and Weak Cooperators and the one of Fischbacher et al. (2001) which identifies CC, FR and TC types. Non Cooperators correspond to FRs, Strong Cooperators to CC types, and Weak Cooperators to TCs.
} 


\section{Experimental design}

The voluntary contribution game was played in groups of four participants. Each group member was endowed with 20 tokens that he had to allocate between his private account and a collective account. Each token allocated to the private account provided a sure outcome of 1 point. Each token allocated to the collective account provided 0.5 points to each group member. The gain of group member $i$ was therefore:

$$
u_{i}\left(g_{i}, g_{-i}\right)=20-g_{i}+0.5\left(g_{i}+g_{-i}\right)
$$

where $g_{i}$ is the contribution of player $i$ to the collective account, and $g_{-i}$ the total contribution of the other group members to the collective account.

The experiment was split into two stages. In stage 1 we relied on the contribution game to elicit behavioral types, and in stage 2 the contribution game was played over 20 rounds following a real-time procedure similar to the one employed by Rivas and Sutter (2011).

\section{Stage 1: Elicitation of behavioral types}

Stage 1 is a replication of the procedure of Fischbacher et al. (2001) which is intended to elicit each subject's behavioral type. Subjects were asked to make two types of decisions in the one shot contribution game: an "unconditional contribution" and a "conditional contribution". First, each subject was asked to choose an unconditional contribution, i.e. the amount he wanted to contribute to the collective account. Second, each subject was asked to make a conditional contribution for each possible average contribution of the other members of his group, rounded to integer numbers, i.e., for $0,1, \ldots, 20$ contributed on average. After all group members had decided about both types of contributions, one of the subjects, say subject $i$, was randomly chosen to be the conditional contributor, while the other group members were assigned to the role of unconditional contributors for that stage. Subject $i$ 's gain was determined according to his conditional contribution with respect to the average unconditional contribution of the other members. Similarly, each other group member's payoff was determined according to his unconditional contribution and the other group members contributions. Each group member earned therefore a gain corresponding to his contribution decision and the contribution decisions of the other group members. Following Fischbacher et al. (2001) we rely on each subject's response to classify him either as a free rider (FR), a conditional cooperator (CC), a triangle contributor (TC) or as other $(\mathrm{O})^{4}$.

\section{Stage 2: Repeated contribution game with endogenous leadership}

\footnotetext{
${ }^{4}$ The contribution schedule of an FR type contains ' 0 ' in all 21 entries. A CC type has an increasing schedule with a Spearman's $\rho>0$ at p-value $<0.01$. A TC type has a 'hump-shaped' contribution schedule, first increasing up to a certain level (around 10), and decreasing afterwards. All other patterns fall in the "other" category, including unconditional positive contributions.
} 
In stage 2, group members played a real time contribution game according to the following rule: at the beginning of each round subjects were given the opportunity to make their contribution public if they submitted their contribution within 60 seconds. However, only the first mover (named the leader in the sequel) in each group could make his/her decision public. Indeed, as soon as a player took the leadership, the counter immediately disappeared ${ }^{5}$ from the screen; and the contribution of the leader was announced to the three other members of the group (named the followers in the sequel) who next had to choose their contributions simultaneously. If none of the group members had chosen to make a contribution within the 60 seconds time limit, all the group members (named no-leader players hereafter) had to choose their contributions simultaneously. Individual contributions of the four members were displayed in a summary screen, along with the subject's earning before the next round started. The game was repeated for 20 rounds. Each round followed the same procedure.

The experiment was conducted at the University of Montpellier in France in 2010. Subjects were recruited through the online recruitment system ORSEE (Greiner, 2015). Two sessions composed of 5 groups of 4 subjects were organized. A total of 40 students from various disciplines participated to this experiment. None of the subjects had previously participated in a public good experiment and none of them took part in more than one session.

Upon arrival, subjects were randomly seated at visually separated computer terminals. They received written instructions (see Appendix 1) describing the general framework of the contribution game that were read aloud by the experimenter after participants had read them once. Subjects had to answer 10 control questions before receiving the instructions for stage 1 (elicitation of types). Complete anonymity was granted to the participants. They were instructed, after completing the elicitation stage but before knowing their earnings for this first stage, that they would participate in a second stage and that their earnings from both stages would be added up and paid individually at the end of the experiment. The second stage of the experiment consists of 20 rounds repetition of the contribution game. Group composition remained the same throughout the experiment. In both stages, subjects were asked to choose only their contribution to the group account, the remainder of their endowment being automatically invested in their private account.

On average, participants earned $16.99 €$ (5.68€ for stage 1 and $11.31 €$ for stage 2$)$ plus a show up fee ${ }^{6}$. Each session lasted about 2 hours, including the completion of the post-experimental questionnaire and payment of the participants.

Under standard behavioral assumptions, i.e. selfishly oriented rational players, the Nash equilibrium of the simultaneous constituent game implies that each player contributes zero token to the group account. When the game is played sequentially, or in real time as in stage 2 , timing is irrelevant since the best reply for any player is always to contribute zero, either as

\footnotetext{
${ }^{5}$ It was therefore no longer possible for any other group member to become a leader in that round. A limitation of this procedure is that among those who were willing to lead, the fast ones were favored over the slower ones. We however checked that this characteristic is not related to the type of the subject.

${ }^{6}$ The show up fee is equal to $3 €$ or $8 €$ depending on whether the participant is in the location where the experiment took place or was coming from outside.
} 
a first mover (leader) or as a second mover (follower), hence there is no issue of leadership. Under standard game-theoretic assumptions, we expect therefore to observe either a sequence of null contributions, or simultaneous null contributions, or a mixture of the two.

\section{Results}

The presentation of our results is broken down as follows. In subsection 3.1 we report two preliminary results that replicate earlier findings of experimental contribution games involving voluntary leadership. In subsection 3.2 we present our main results which are based on our identification of behavioral types and estimates of the probability to act as a leader according to these types.

\subsection{Preliminary results}

In this subsection we show that our experiment replicates two of the typical findings of "voluntary" leadership experiments: (1) leadership emerges frequently and (2) leaders contribute more than followers.

Result 1: Leadership is frequently observed in every group.

\section{Support for result 1}

Out of the 200 rounds (20 rounds $\times 10$ groups) the absence of a leader was observed in only 9 of them. In $95.5 \%$ of the rounds one of the 4 members announced publicly his contribution to the public good. In 6 groups out of 10 there was a leader in every round, in 2 groups there was no leader in a single round, in one group no leader was observed in 3 of the rounds and in one group there was no leader in 4 of the rounds. Failures of leadership occurred mostly towards the end of the repeated contribution game ${ }^{7}$. Leaders were most of time very quick to take their decision (the average time is less than 10 seconds).

\section{Result 2: Leaders contribute more than followers.}

\section{Support for result 2}

First, observe from figure 1 that the average contribution is larger for leaders than for followers or no-leader players in all rounds. Furthermore, although average contributions tend to decline with the repetition of the game, the decay is much sharper for followers than for leaders. Figure 2 summarizes the average contribution by status (leader, follower or no-leader player). Leaders contribute on average 12.84 tokens which is significantly more (Mann Whitney rank-sum test, 1\%) compared to followers who contribute only 7.18 tokens on average. This result suggests that subjects who are willing to lead want also to give the "good example".

\footnotetext{
${ }^{7}$ Over the ten groups, the first leadership failure occurred as late as round 8. Two failures occurred in round 14, one failure in each of the rounds 16,17 and 18 , and three failures in the final round.
} 
Separate estimates for leaders' and for followers' on the determinants of individual contributions are provided in appendix 2. Interestingly, leader contributions for the CCs do not differ from those of the FRs, while TCs and Os contribute less as leaders. This suggests that a FR who is leading makes a similar contribution than a $\mathrm{CC}$ who leads. By contributing at the same level than the CCs, the FRs trigger the same cooperative climate as CCs. When there is no leader the average contribution collapses at a very low level (1.36 tokens on average) close to the Nash (null) contribution, as already observed by Rivas and Sutter (2011). The failure for a leader to emerge seems therefore to be a very bad signal that ruins cooperation among group members.

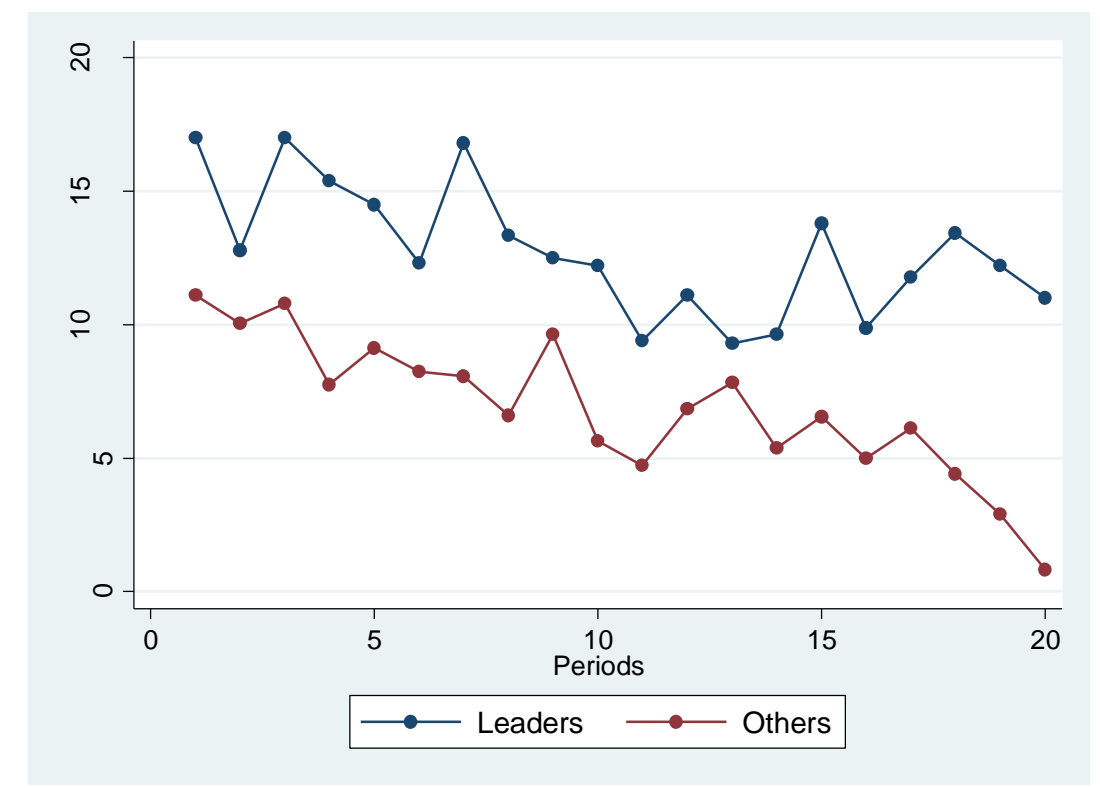

Figure 1 Average per period contribution of leaders and others (followers and no-leader players)

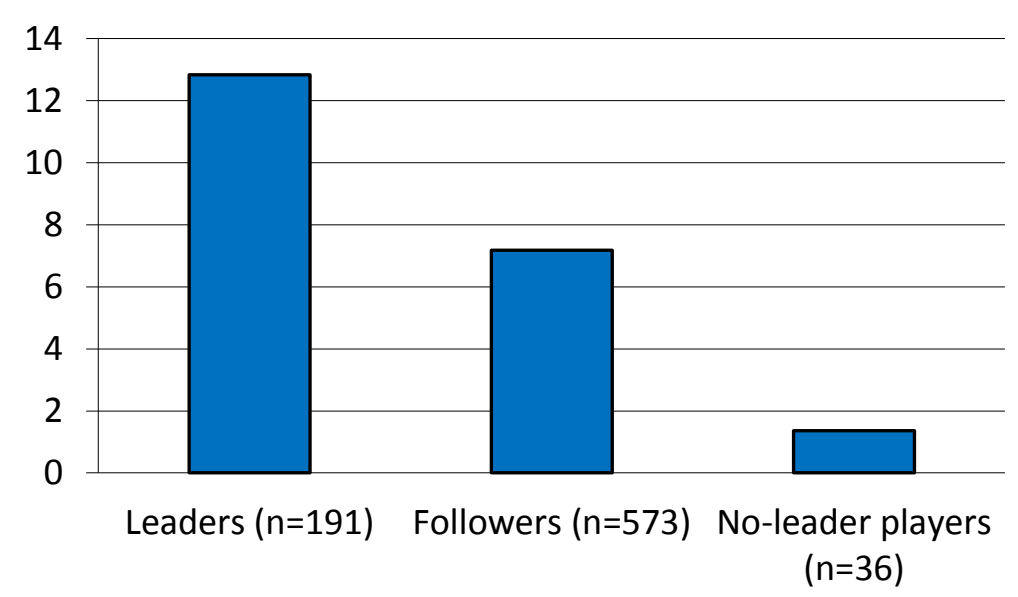

Figure 2 Mean contributions by status. 


\subsection{Main result}

We first provide statistics about behavioral types before showing how the probability to act as a leader depends on types.

\subsubsection{Behavioral types}

The frequency of each behavioral type elicited in the first stage of our experiment is summarized in Table 1. Figure 3 shows the average contribution pattern for each of the behavioral types. The frequencies in table 1 are similar to those found earlier by Fischbacher et al. (2001) and Fischbacher and Gächter (2010). Kocher et al. (2008) showed however that the distribution of player types may differ across countries: for instance they found that there are more conditional cooperators in their U.S location than in their Austrian and Japanese locations. We also find a significant difference in type frequencies between our sample and the Kocher et al.'s (2008) US sample which contains a higher frequency of conditional cooperators compared to our sample of French student subjects. However there is no significant difference in type frequencies between our sample and the Kocher et al. (2008) Austrian and Japanese samples (Chi-squared test with 3 degrees of freedom ${ }^{8}$ at the 5\% significance level). Furthermore, there is neither a significant difference in type frequencies between our sample and the Fischbacher et al. (2001) sample, nor between our sample and the Fischbacher and Gächter (2010) sample.

Table 1 Distribution of behavioral types

\begin{tabular}{ccccc}
\hline \multirow{2}{*}{ Type } & \multirow{2}{*}{ Number } & Percent & \multicolumn{2}{c}{$\begin{array}{c}\text { Unconditional } \\
\text { contribution } \\
\end{array}$} \\
& & & Mean & St.dev. \\
\hline FR & 9 & $22.5 \%$ & 4.66 & 6.93 \\
CC & 15 & $37.5 \%$ & 13.40 & 5.07 \\
TC & 6 & $15.0 \%$ & 9.00 & 6.81 \\
O & 10 & $25.0 \%$ & 9.70 & 4.74 \\
\hline Total & 40 & $100 \%$ & 9.85 & 6.35 \\
\hline
\end{tabular}

\footnotetext{
${ }^{8}$ The number of degrees of freedom is equal to $(r-1)(k-1)$ where $r$ is the number of samples to compare and $k$ the number of types.
} 


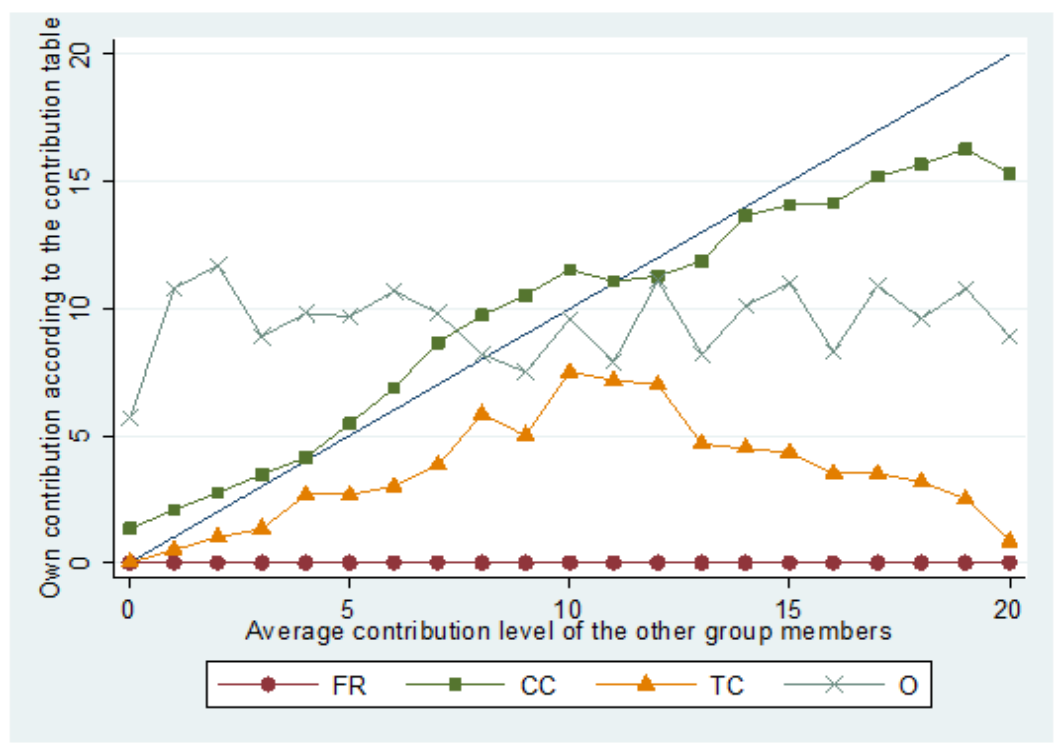

Figure 3 Average contribution pattern by types.

Since subjects were randomly matched into groups at the beginning of the experiment, we have 10 heterogeneous groups.

\subsubsection{Relation between behavioral types and voluntary leadership}

Result 3: Conditional cooperators are more likely to act as leaders than other types.

\section{Support for result 3}

Our data (see Figure 4) show that the frequency of being a leader conditionally on the subject's type is twice larger for a CC type (0.32) than for a FR type $(0.16)$. The probability of being leader is 0.18 for a TC type and 0.22 for an $\mathrm{O}$ type.

Let us define the conditional probability $\mathrm{P}($ Leader|Type), where Leader $=1$ if player $i$ acts as a leader and Type $\in\{\mathrm{FR}, \mathrm{CC}, \mathrm{TC}, \mathrm{O}\}$. The statement " $\mathrm{CC}$ are more likely to act as a leader than other types" can be restated by the three inequalities: $\mathrm{P}($ Leader $\mid \mathrm{CC})>\mathrm{P}($ Leader $\mid \mathrm{FR})$, $\mathrm{P}($ Leader $\mid \mathrm{CC})>\mathrm{P}($ Leader $\mid \mathrm{TC})$ and $\mathrm{P}($ Leader $\mid \mathrm{CC})>\mathrm{P}($ Leader $\mid \mathrm{O})$. The three inequalities are significant: $\mathrm{p}=1,0.999$, and 0.99 , respectively (Fisher exact test ${ }^{9}$ ).

All CC subjects acted as leaders at least once. Three subjects out of 40 (1 FR, 1 TC and $1 \mathrm{O}$ ) never acted as a leader. No subject was a permanent leader, i.e. for 20 rounds. At most two CC succeeded to lead in 13 rounds out of 20.

\footnotetext{
${ }^{9}$ The binomial test leads to the same conclusion.
} 


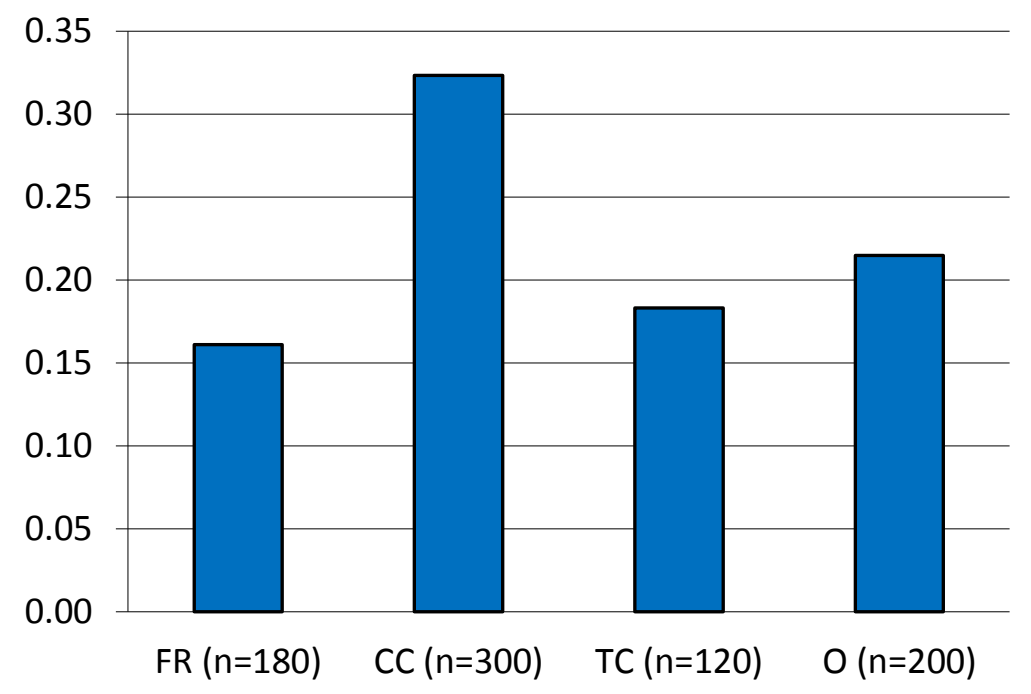

Figure 4 Frequency of acting as a leader by type.

We provide further statistical support for result 3 by estimating the probability of being leader conditional to the behavioral types. Let $y_{i t}$ be the leader dummy variable, which is equal to 1 if $i$ was a leader in round $t$ and zero otherwise $(i=1,2, \ldots, 40$ and $t=1, \ldots, 20)$. We estimate the following model:

$$
y_{i t}=\left\{\begin{array}{lll}
1 & \text { if } & y_{i t}^{*}>0 \\
0 & \text { if } & y_{i t}^{*} \leq 0
\end{array}\right.
$$

where the latent variable $y_{i t}^{*}$ represents the utility difference for subject $i$ if he chooses to act as a leader rather than as a follower. The latent equation is

$$
y_{i t}^{*}=\mathbf{z}_{i t}^{\prime} \gamma+\mu_{i}+u_{i t}
$$

where bold characters stand for vectors; $\mu_{i}$ is the individual random effect $\left(\mu_{i} \sim \mathrm{N}\left(0, \sigma_{\mu}^{2}\right)\right)$. Note also that the regression error is idiosyncratic, i.e. $u_{i t} \sim \mathrm{N}\left(0, \sigma_{u}^{2}\right)$.

The probability of being leader is then estimated by:

$$
P\left(y_{i t}=1 \mid y_{i, t-1}, \mathbf{z}_{i t}, \mu_{i}\right)=\Phi\left(\rho y_{i, t-1}+\mathbf{z}_{i t}^{\prime} \gamma+\mu_{i}\right)
$$

The above model is a probit model generalized to the dynamic setting corresponding to our repeated game. The purpose of this dynamic specification is to account for interactions between subjects and subject's decisions in the previous round. Variables in $\mathbf{z}_{i t}$ include subject's characteristics. ${ }^{10}$ We estimate the model by relying on the method of Wooldridge (2005) which consists in specifying the density of $\mu_{i}$ conditionally on $y_{i 1}$ (the initial choice) and $\mathbf{z}_{i}\left(\equiv\left(\mathbf{z}_{i 1}, \ldots, \mathbf{z}_{i T}\right)\right)$ :

$$
\mu_{i} \mid y_{i 1}, \mathbf{z}_{i} \sim \mathrm{N}\left(\alpha_{0}+\alpha_{1} y_{i 1}+\mathbf{z}_{i}^{\prime} \boldsymbol{\alpha}_{2}, \sigma_{\mu}^{2}\right)
$$

\footnotetext{
${ }^{10}$ We estimated the same model by adding the contributions of other subjects in the previous period in $\mathbf{z}_{i t}$. However, this variable was not significant and did not affect the overall results presented above.
} 
Hence, estimation of the dynamic model should include the initial value of the dependent variable (corresponding to $\alpha_{1}$ ) and additional regressors defined from the original set of explanatory variables (corresponding to $\left.\boldsymbol{\alpha}_{2}\right)^{11}$. Table $4^{12}$ summarizes the estimates of the parameters of the model as well as the marginal effects for the explanatory variables on the probability of being a leader. The probability for $i$ to act as a leader in round $t$ is higher if $i$ was a leader in the first round and if he was not a leader in the previous round $(t-1)$. This means that a subject who took the leadership in the first round had a higher probability of being a leader in later periods. However we observe some alternation between group members for moving first. All other things being equal, being a CC type has a significantly positive effect $(=0.881)$ compared to a FR type (the reference type). Moreover, the marginal effect of the CC type on the probability of acting as a leader is significant and positive $(=0.239)$ whereas the marginal effects of other behavioral types are statistically insignificant. We chose FR as the reference type because it corresponds to the Nash prediction (assuming standard behavioral assumptions). However, if the CC type is taken as the reference type, the results of the dynamic panel probit model shows that the probability of being leader for a CC type is significantly larger than for TC and $\mathrm{O}$ types. A comparison between TC and O does not show any significant difference for the probability of being leader. These findings corroborate the previous analysis based on Figure 4, i.e. CC types act more frequently as leaders than all other types $^{13}$. Although the absence of a leader occurs mostly towards the end of the repeated contribution game, the variable Trend which corresponds to the round numbering is not significant because leadership remains frequently observed until the end of the experiment. Surprisingly, the variable Unconditional contribution impacts negatively the probability of being leader, but this result is not robust and is significant only at the $10 \%$ level $^{14}$.

\footnotetext{
${ }^{11}$ According to a likelihood ratio test, our dynamic specification outperforms the static model. Under the null hypothesis corresponding to the static model, $H_{0}: \rho=\alpha_{0}=\alpha_{1}=\alpha_{2}=0$, the test statistic follows a $\chi^{2}$ distribution with 22 degrees of freedom. The computed statistic is 93.868 and the corresponding p-value almost 0 , leading to the rejection of the static model in favor of our dynamic specification.

${ }^{12}$ Table 4 does not report the estimates for $\boldsymbol{\alpha}_{2}$ associated to $\mathbf{z}_{i}$, because $\mathbf{z}_{i}$ is the set of auxiliary regressors needed in modelling the distribution of individual effects conditional on the initial choice $y_{i 1}$ (following Wooldridge, 2005). They are only of statistical interest (available from the authors upon request).

${ }^{13}$ In order to control for a possible group composition effect for this result, we included a variable corresponding to the number of $\mathrm{CC}$ in the group (1, 2 or 3). Because this variable was insignificant, we decided to not report the results of the corresponding regression. We also checked that the variable corresponding to the number of FR in the group was not significant. We also estimated a model including group dummies, but it did not converge (the likelihood function was not concave). Overall, the lack of significance of group dummies can be due to our small sample size.

${ }^{14}$ As pointed out by one of the reviewers, the multicollinearity between the variable "Unconditional contribution" and the subjects' types may explain the surprising result that the unconditional contribution is negatively related to willingness to lead.
} 
We included several control variables that we expected to influence the probability to act as a leader independently of the behavioral type: gender, education and birth rank in siblings. The only significant variable is Eldest, a dummy variable which is equal to one if the subject with siblings is the eldest. A subject who is only child is not considered as "eldest". Eldest appear to be more often leaders. This result seems reasonable because eldest children are probably more often required to give a good example. We also observe a significant effect related to the level of studies: graduate students (master and $\mathrm{PhD}$ level) are less often leaders than undergraduate students.

Table 4 Probability of being leader

\begin{tabular}{lllll}
\hline \hline Variable & Coefficient & (Std. Err.) & Marginal effect & (Std. Err.) \\
\hline Leader in first round & $1.259^{* * *}$ & $(0.276)$ & $0.342^{* * *}$ & $(0.072)$ \\
Leader in previous round & $-0.340^{* *}$ & $(0.136)$ & $-0.092^{* *}$ & $(0.037)$ \\
Contrib. in previous round & 0.014 & $(0.009)$ & 0.004 & $(0.003)$ \\
Type CC & $0.881^{* *}$ & $(0.354)$ & $0.239^{* *}$ & $(0.095)$ \\
Type TC & 0.079 & $(0.319)$ & 0.021 & $(0.087)$ \\
Type O & 0.175 & $(0.258)$ & 0.048 & $(0.070)$ \\
Trend & -0.004 & $(0.010)$ & -0.001 & $(0.003)$ \\
Unconditional contribution & $-0.047 *$ & $(0.028)$ & $-0.013 *$ & $(0.007)$ \\
Female & -0.152 & $(0.195)$ & -0.041 & $(0.053)$ \\
Eldest & $0.711^{* * *}$ & $(0.275)$ & $0.193 * * *$ & $(0.074)$ \\
Number of brothers/sisters & 0.104 & $(0.090)$ & 0.028 & $(0.024)$ \\
Graduate student & $-0.809^{* * *}$ & $(0.260)$ & $-0.220 * * *$ & $(0.070)$ \\
Intercept & $-0.819^{* *}$ & $(0.407)$ & & \\
$\ln \sigma_{\mu}^{2}$ & -14.659 & $(29.008)$ & & \\
\hline LR $\chi^{2}(22)$ & $93.868^{* * *}$ & & & \\
Log-likelihood & -369.065 & & & \\
Number of individuals & 40 & & & \\
Number of observations & 760 & Notes: Standard errors are in parentheses. \\
\hline \multicolumn{5}{c}{ The likelihood ratio (LR) statistic compares the static model to the dynamic model. } \\
Significant levels: * $p<0.10, * * p<0.05, * * * p<0.01$. &
\end{tabular}

Finally, we estimated the leaders' contributions of leaders and the followers' contributions based on a censored dynamic panel model with random individual effects (appendix 2). As observed in previous experiments, leaders contribute much more than followers, a fact that we interpret as attempts by leaders to set a good example. Although the CC types are the most frequent to lead, they are not the "best leaders" compared to the $\mathrm{O}$ types who contribute significantly more as leaders than the other types.

\section{Conclusion}

We designed a repeated real time public goods experiment in order to identify who are the leaders. In every round subjects were given the opportunity to voluntarily contribute before others to the public good and let their decision become common knowledge. We observed that leaders emerge in almost every round and that most subjects were willing to move first (at 
least once). Fewer than $5 \%$ of the rounds had no leader, a situation that happened mostly towards the end of the repeated game. Our key finding is that conditional cooperators are more likely to act as a leader than other types. We showed this result by eliciting subjects' behavioral types and estimating the probability of acting as a leader based on a dynamic probit model with individual random effects.

We interpret the fact that the leaders' contributions are significantly higher than the followers' contributions as evidence that leaders were willing to signal their cooperativeness by showing the good example. The repeated structure of the game however, allows for an alternative interpretation: strategic subjects have an incentive to lead and make high contributions in early rounds in order to induce a cooperative climate in their group from which they can benefit in later rounds by free riding on others' contribution. But the data shows an insignificant negative (almost null) trend in the probability to lead as the game is repeated (see Table 4), suggesting that most leaders do not act strategically, but in contrast try to induce sustained cooperation throughout the game. The fact that CC types are more likely to lead than other types remains puzzling. We argued in the introduction that CC types are more likely to "wait and see" when they have an opportunity to do so, precisely because they are in a better position to condition their contribution on a leader's. How can we therefore explain that $\mathrm{CC}$ types do not often act in this way, but rather seem to be frequently willing to lead by example? A possible reason, as shown by Gächter et al. (2012), is that CCs are more optimistic about others contributions. Another reason is that conditional cooperativeness is correlated to unconditional cooperativeness within subjects. Indeed, we observe (see Table 1) that the mean unconditional contribution is significantly larger for CC types than for the other types (Mann Whitney rank-sum test: Prob $>|z|=0.0060$ ). Therefore, the fact that CCs are more cooperative combined to the fact that they are probably also more optimistic with respect to others' cooperativeness, could explain why $\mathrm{CCs}$ are more frequently action as leaders.

Our results contribute to a better understanding of leadership in voluntary and sequential contributions environments, a situation that is frequently encountered in real life. It is well known that variables such as the rank and number of siblings, gender or age, affect leadership behavior. We show that behavioral types have also a strong impact on leadership, both as a key determinant of the probability to act as a leader and as a determinant of contributions of leaders versus followers.

\section{Acknowledgements}

We would like to thank Dimitri Dubois for his assistance in programming and running the experiments. Thanks also to Daniele Nosenzo who made some useful comments and suggestions on an earlier version of this paper. The comments and suggestions of two anonymous referees were very helpful to improve the paper. 


\section{Appendix 1: Instructions for the experiment}

\section{Instructions for stage 1 (elicitation phase)}

The elicitation phase, i.e. the strategy method used to elicit subjects' behavioral types, is based on the P-Experiment of Fischbacher and Gächter (2010). Instructions have been translated into French and slightly adapted. They are available upon request.

In the French instructions we rather use the words "individual account" and "collective account" instead of "private account" and "project". We also replaced the verb "to invest" by "to put", which appears more neutral in French. For the same reasons we did not use the word “contribution". In addition, endowments are expressed in tokens and gains in points.

In order to make comparison with a previous experiment (Masclet et al., 2012), we fixed the marginal rate of the collective account to 0.5. This rate is 0.4 in Fishbacher and Gächter (2011).

Finally, in this first phase of the experiment, 1 point $=0.20$ euro.

Control questions were identical.

\section{Instructions for stage 2 (voluntary contribution game)}

We will now conduct another experiment. This experiment lasts 20 rounds. Each round, you and the 3 other members of your group will have to decide how many tokens, out of your 20 endowment tokens, you put in the collective account. The tokens left are automatically put on your individual account. The composition of your group is the same than in the previous experiment and will not change until the end of the experiment. Your total income in each round is the sum of your income from your individual account and your income from the collective account. Your final gain for this experiment will be the sum of your incomes (in points) in the 20 rounds. The total of your cumulated points will be converted into euros at the following rate:

\section{1 point $=2$ cents of euros}

\section{The sequence/procedure of a round}

The decision

Each round, each member of your group (you included) must decide how many tokens to put in the collective account.

The first decision taken within the 60 first seconds will be displayed in a table on your screen. As soon as a member of your group takes a decision, an informative window appears on your screen. Then you must click on the button "OK" to validate that you received the information. As soon as you validate, the informative window closes and the decision which has been taken becomes visible in the table. Only the first decision taken during the 60 seconds will be 
displayed in the table. A scroll bar displayed on your screen indicates the remaining time before the end of the 60 seconds. The decision screen which you will see in every round looks like Figure A1 [not reproduced here]. As soon as a member of your group takes a decision, or at the end of the 60 seconds, the scroll bar will disappear and the members who did not take their decision must do it at this moment. Nevertheless, those decisions will not be visible in the table. If none of the group member took his decision within the 60 seconds, no information will be displayed on the screen. In that case all members of the group must take their decision without information on the decision of others.

Note that once you validate your decision you cannot change it for the on-going round.

\section{Summary of the round}

When all the participants have taken their decision a summary will be displayed. Figure A2 [not reproduced here] shows how this summary looks like. It reminds you the allocation you decided between your individual account and the collective account. It informs you about the total number of tokens put in the collective account by your group, about the details of the decision of each member of your group and computes your income for the round. When all participants have clicked on the button "next round" of this screen, the next round starts.

Note that from the summary screen you can consult the history of previous rounds by clicking on the button "history" at the upper right corner of the screen. The history screen looks like Figure A3 [not reproduced here].

When the $20^{\text {th }}$ round is over, the experiment is finished. Your total income for the experiment will be the sum of your income from the first experiment and the one of the second experiment. A screen will give your income in each of the two experiments and will convert your final gain into euros. 


\section{Appendix 2: Effects of endogenous leadership on contributions}

We study the impact of various possible explanatory variables on the level of contribution. We use a dynamic specification in order to account for interactions between subjects and subject's decisions in the previous round. ${ }^{15}$ Let $c_{i t}$ be the contribution of subject $i$ in round $t$ $(i=1,2, \ldots, 40$ and $t=1, \ldots, 20)$. Because the contribution must be chosen within the set $\{0$, $\ldots, 20\}$ we rely on a censored dynamic panel model:

$$
c_{i t}=\left\{\begin{array}{ccc}
0 & \text { if } & c_{i t}^{*} \leq 0 \\
c_{i t}^{*} & \text { if } & 0<c_{i t}^{*}<20 \\
20 & \text { if } & c_{i t}^{*} \geq 20
\end{array}\right.
$$

with the latent model

$$
c_{i t}^{*}=\rho c_{i, t-1}+\mathbf{z}_{i t}^{\prime} \boldsymbol{\gamma}+\lambda_{i}+v_{i t}
$$

where bold characters correspond to vectors, $\lambda_{i}$ represents a random individual effect, and $v_{i t}$ is the standard regression error, $v_{i t} \sim N\left(0, \sigma_{v}^{2}\right)$. Following Wooldridge (2005), the likelihood for each individual is

$$
\prod_{t=1}^{T} f_{t}\left(c_{i t} \mid z_{i t}, \mathrm{c}_{i, t-1}, \lambda_{i} ; \boldsymbol{\theta}\right)
$$

where $\boldsymbol{\theta}$ includes the whole set of parameters to be estimated. To estimate the model we need to integrate the likelihood with respect to $\lambda_{i}$. We therefore require an additional assumption about the distribution of $\lambda_{i}$ conditional on $\left(c_{i 1}, \boldsymbol{z}_{\boldsymbol{i}}\right)$, that is $h\left(\lambda_{i} \mid c_{i 1}, \boldsymbol{z}_{\boldsymbol{i}} ; \boldsymbol{\delta}\right)$ where $\boldsymbol{\delta}$ is the associated set of parameters and $\mathbf{z}_{i} \equiv\left(\mathbf{z}_{i 1}, \ldots, \mathbf{z}_{i T}\right)$. Hence, the individual likelihood becomes

$$
l_{i}(\boldsymbol{\theta}, \boldsymbol{\delta})=\int\left(\prod_{t=1}^{T} f_{t}\left(c_{i t} \mid \mathbf{z}_{i t}, c_{i, t-1}, \lambda_{i} ; \boldsymbol{\theta}\right)\right) h\left(\lambda_{i} \mid c_{i 1}, \mathbf{z}_{\boldsymbol{i}} ; \boldsymbol{\delta}\right) \eta\left(d \lambda_{i}\right) .
$$

As in Wooldridge (2005), we assume the conditional density of $\lambda_{i}$ as

$$
\lambda_{i} \mid c_{i 1}, z_{i} \sim N\left(\alpha_{0}+\alpha_{1} c_{i 1}+z_{i}^{\prime} \alpha_{2}, \sigma_{\lambda}^{2}\right) .
$$

We estimate separately the model for the leader's contribution (Table 5) and for the follower's contribution (Table 6). We observe that the dynamic specification imposes the inclusion of the initial value of the dependent variable (corresponding to $\alpha_{1}$ ) and other additional regressors defined from the original set of explanatory variables (corresponding to $\boldsymbol{\alpha}_{2}$ ). Results for $\boldsymbol{\alpha}_{2}$ are not reported here as they are of little importance.

\footnotetext{
${ }^{15} \mathrm{We}$ do not include contributions of other players in the previous round in the set of explanatory variables because of multicolinearity.
} 
Table 5 Effects on leader's contribution

\begin{tabular}{lll}
\hline \hline Variable & Coefficient & (Std. Err.) \\
\hline Contribution in first round & -0.181 & $(0.231)$ \\
Contribution in previous round & 0.158 & $(0.107)$ \\
Type CC & -1.168 & $(3.887)$ \\
Type TC & $-7.864^{*}$ & $(4.072)$ \\
Type O & $8.088^{* *}$ & $(3.587)$ \\
Trend & $-0.471^{* * *}$ & $(0.122)$ \\
Female & $-11.231^{* * *}$ & $(2.672)$ \\
Eldest & $-6.366^{* *}$ & $(2.907)$ \\
Number of brothers/sisters & 0.037 & $(1.335)$ \\
Graduate student & 0.273 & $(3.001)$ \\
Intercept & $9.521^{*}$ & $(5.120)$ \\
$\sigma_{\lambda}$ & 0.000 & $(0.692)$ \\
$\sigma_{v}$ & $7.228^{* * *}$ & $(0.552)$ \\
\hline LR $\chi^{2}(20)$ & $104.516^{* * *}$ & \\
Log-likelihood & -407.820 & \\
Number of individuals & 37 & \\
Number of observations & 181 & \\
\hline \hline
\end{tabular}

Notes: Standard errors are in parentheses.

The likelihood ratio (LR) statistic compares the static model to the dynamic model. Significant levels: $* p<0.10, * * p<0.05, * * * p<0.01$.

Table 6 Effects on follower's contribution

\begin{tabular}{lll}
\hline \hline Variable & Coefficient & (Std. Err.) \\
\hline Contribution in first round & $0.238^{*}$ & $(0.129)$ \\
Contribution in previous round & 0.047 & $(0.062)$ \\
Type CC & 1.457 & $(1.642)$ \\
Type TC & 2.564 & $(2.160)$ \\
Type O & 1.357 & $(1.772)$ \\
Trend & $-0.418^{* * *}$ & $(0.073)$ \\
Leader's contribution & $0.553^{* * *}$ & $(0.065)$ \\
Female & -0.566 & $(1.384)$ \\
Eldest & 1.049 & $(1.508)$ \\
Number of brothers/sisters & -0.758 & $(0.679)$ \\
Graduate student & $-3.328^{*}$ & $(1.727)$ \\
Intercept & $-8.750^{* * *}$ & $(2.697)$ \\
$\sigma_{\lambda}$ & 0.000 & $(0.508)$ \\
$\sigma_{v}$ & $7.567 * * *$ & $(0.340)$ \\
\hline LR $\chi^{2}(20)$ & $258.909^{* * *}$ & \\
Log-likelihood & -1178.726 & \\
Number of individuals & 40 & \\
Number of observations & 543 & \\
\hline \hline
\end{tabular}

Notes: Standard errors are in parentheses.

The likelihood ratio (LR) statistic compares the static model to the dynamic model. Significant levels: $* p<0.10, * * p<0.05, * * * p<0.01$.

The two first variables are lagged variables that should allow us to take into account interactions between group members during the experiment. Note that the leader (Table 5) and the follower (Table 6) can have been leader or follower in the first round (Contribution in the first round) and in the previous round (Contribution in the previous round). Leaders' and 
followers' contributions significantly decline over time (negative trend). As expected, the followers' contribution is significantly and positively affected by the leader's contribution (Table 6). Even if we control for the decline of leaders' contributions, followers also significantly decrease their contributions from round to round. Thus, as observed in Figure 1, voluntary leadership does not prevent decay. As leaders there is no significant difference between $\mathrm{CC}$ and FR (the reference type): only leaders of type $\mathrm{O}$ contribute significantly more than FR leaders. Apparently TC leaders contribute less than FR leaders (significant only at $10 \%$ ), but this result is not robust and seems to be linked to the strong gender effect observed for the leader's contribution. Note that behavioral type does not have a significant impact on followers' contributions which depend essentially on the leader's contribution.

Our models also include several demographic control variables that are likely to affect contributions. Demographic variables that have a significant impact on contributions are different for leaders and for followers. On the one hand female leaders contribute significantly less than male leaders, but there is no gender difference in contributions for followers. On the other hand, a larger number of siblings lowers the followers' contributions. Finally, graduate followers contribute less than undergraduate followers, but education does not have any significant impact on the leader's contribution.

In tables 5 and 6 we report the results of the likelihood ratio test comparing our dynamic specification to the static model, for leader's contribution and follower's contribution respectively. The null hypothesis for the static model is $H_{0}: \rho=\alpha_{0}=\alpha_{1}=\alpha_{2}=0$ and the test statistic is a $\chi^{2}$ distribution with 20 degrees of freedom. The computed statistics are equal to 104.516 and 258.909 for leaders' contribution and for followers' contribution, respectively. Both tests give a p-value very close to 0 , implying that the static model is rejected in favor of our dynamic specification.

\section{References}

Alpizar, F., Carlsson F., Johansson-Stenman O. (2008). "Anonymity, reciprocity, and conformity: Evidence from voluntary contributions to a national park in Costa Rica." Journal of Public Economics, 92:5-6, 1047-1060.

Arbak E., Villeval M.-C. (2013), "Voluntary leadership: motivation and influence." Social Choice and Welfare, 40, 635-662.

Dannenberg, A. (2015), "Leading by example versus leading by words in voluntary contribution experiments", Social Choice and Welfare, 44, 71-85.

Drouvelis M., Nosenzo D. (2013). "Group identity and leading-by-example." Journal of Economic Psychology, 39, 414-425.

Fischbacher U., Gächter S. (2010), "Social preferences, beliefs, and the dynamics of free riding in public good experiments." American Economic Review, 100, 541-556. 
Fischbacher U., Gächter S., Fehr E. (2001), "Are people conditionally cooperative? Evidence from a public goods experiment." Economics Letters, 71:3, 397-404.

Frey B.S., Meier S. (2004). "Social comparisons and pro-social behavior. Testing 'conditional cooperation' in a field experiment." American Economic Review, 94:5, 1717-1722.

Gächter S., Nosenzo D., Renner E., Sefton M. (2010), "Sequential Versus Simultaneous Contributions to Public Goods: Experimental Evidence." Journal of Public Economics, 94:78, 515-522.

Gächter S., Nosenzo D., Renner E., Sefton M. (2012), "Who makes a good leader? Cooperativeness, optimism and leading-by-example." Economic Inquiry, 50:4, 953-967.

Gächter S., Renner E. (2003), "Leading by example in the presence of free rider incentives." Paper presented at a Conference on Leadership, March 2003, Lyon.

Gächter S., Renner E. (2007), "The Role of Leadership and Beliefs in the Voluntary Provision of Public Goods." Mimeo, University of Nottingham.

Greiner B. (2015), “Subject Pool Recruitment Procedures: Organizing Experiments with ORSEE”. Journal of the Economic Science Association, 1(1), 114-125.

Güth W., Levati M. V., Sutter M., van der Heijden E. (2007), "Leading by example with and without exclusion power in voluntary contribution experiments." Journal of Public Economics, 91:5-6, 1023-42.

Haigner S. D., Wakolbinger F. (2010), "To lead or not to lead." Economics Letters, 108:1, 9395.

Keser, C., \& van Winden, F. (2000). "Conditional Cooperation and Voluntary Contributions to Public Goods”. Scandinavian Journal of Economics, 102:1, 23-39.

Kocher M. G., Cherry T., Kroll S., Netzer R. J., Sutter M. (2008), "Conditional cooperation on three continents." Economics Letters, 101, 175-178.

Kumru C., Vesterlund L. (2010), "The Effect of Status on Charitable Giving." Journal of Public Economic Theory, 12:4, 709-735.

Levati M. V., Sutter M., van der Heijden E. (2007), "Leading by Example in a Public Goods Experiment with Heterogeneity and Incomplete Information." Journal of Conflict Resolution, 51:5, 793-818.

Martin R., Randal J. (2008), "How is donation behaviour affected by the donations of others?" Journal of Economic Behavior and Organization, 67:1, 228-238.

Masclet D., Willinger M., Figuières C. (2012), "Vanishing leadership and declining reciprocity in a sequential contribution experiment." Economic Inquiry, 50:3, 567-584.

Moxnes E., van der Heijden E. (2003), "The Effect of Leadership in a Public Bad Experiment." Journal of Conflict Resolution, 47:6, 773-95.

Neugebauer, T., Perote, J., Schmidt, U., \& Loos, M. (2009). "Selfish biased conditional cooperation: On the decline of cooperation in repeated public goods experiments". Journal of Economic Psychology, 30:1, 52-60. 
Pogrebna, G., Krantz, D.H., Schade, C., Keser, C. (2011). "Words versus actions as a means to influence cooperation in social dilemma situations." Theory and Decision 71:4, 473-502.

Potters J., Sefton M., Vesterlund L. (2005), "After you--endogenous sequencing in voluntary contribution games. Journal of Public Economics, 89, 1399-1419.

Potters J., Sefton M., Vesterlund L. (2007), "Leading-by-example and signaling in voluntary contribution games: an experimental study." Economic Theory, 33:1, 169-82.

Rivas M. F., Sutter M. (2011), "The benefits of voluntary leadership in experimental public goods games." Economics Letters, 112: 2, 176-178

Shang J., Croson R. (2009), "A field experiment in charitable contribution: the impact of social information on the voluntary provision of public goods." The Economic Journal, 119, $1422-1439$.

Wooldridge J. M. (2005). "Simple solutions to the initial conditions problem in dynamic, nonlinear panal data models with unobserved heterogeneity." Journal of Applied Econometrics, 20, 39-54. 